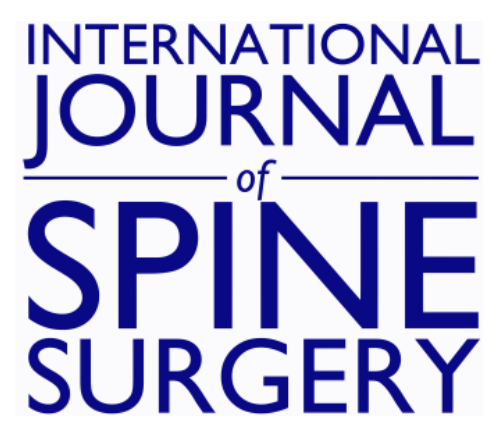

\title{
Kineflex (Centurion) Lumbar Disc Prosthesis: Insertion Technique and 2-Year Clinical Results in 100 Patients
}

Ulrich R. Hähnle, Ian R. Weinberg, Karen Sliwa, Barry MBE Sweet and Malan de Villiers

Int J Spine Surg 2007, 1 (1) 28-35

doi: https://doi.org/10.1016/SASJ-2006-0005-RR

http://ijssurgery.com/content/1/1/28

This information is current as of April 26, 2023.

Email Alerts Receive free email-alerts when new articles cite this article. Sign up at:

http://ijssurgery.com/alerts 


\title{
Kineflex (Centurion) Lumbar Disc Prosthesis: Insertion Technique and 2-Year Clinical Results in 100 Patients
}

\author{
Ulrich R. Hähnle, MD, FCS (Ortho), Ian R. Weinberg, MD, FCS (Neuro), \\ Karen Sliwa, MD, PhD, Barry MBE Sweet, MD, PhD, and Malan de Villiers, PhD
}

\section{ABSTRACT}

\section{Background}

The Kineflex lumbar disc is a mechanical, unconstrained, re-centering disc prosthesis developed in South Africa. The first implantation took place in October 2002. We present a single-center, prospective, longitudinal study of the first 100 patients treated with the Kineflex lumbar disc. Our objective was to evaluate the insertion technique, clinical outcomes, and patient satisfaction at 2 years postimplantation in 100 consecutive patients with 132 (68 single- and 32 2-level) Kineflex lumbar disc replacements.

\section{Methods}

We determined the exact central placement of all disc implants in the coronal and midsagittal planes. We measured clinical outcome with the Oswestry disability index (ODI), our own questionnaire, and the time needed to return to work. All patients received radiological and clinical follow-up assessments for 2 years after the index procedure.

\section{Results}

Forty-three patients were female. The mean age of the patients at operation was 44.9 years (range, 23-63 years). Postoperative hospitalization averaged 2.8 days (range, 2 to 8 days). All patients who were employed before surgery returned to work $31 \pm 16.8$ days after the operation. Fifty-six percent of operated disc levels had intervertebral disc heights of less than $5 \mathrm{~mm}$. A 2-year clinical outcome was available for 98 of the 100 patients ( 58 excellent, 30 good, 7 fair, 3 poor). The ODI score improved from $47.8 \pm 16.0$ preoperatively to $14.2 \pm 14.0(P<.01)$ at 2 years. At 2 years, 95\% of disc implants were radiologically in the ideal position. The insertion technique, with a released prosthetic mechanism for final placement, allowed ideal placement in the sagittal plane in $98 \%$ of discs. The radiographic placement accuracy achieved was equal in patients with preoperative intervertebral disc height below and above $5 \mathrm{~mm}$.

\section{Conclusions}

Good short-term clinical results were achieved with the Kineflex disc in a heterogeneous patient group with a high number of patients with advanced disc degeneration, severe disc space narrowing, and lumbar flat-back deformity. In this cohort, accurate implant placement could be achieved in our first 100 patients.

\section{Clinical Relevence}

This is the first report on the Kineflex mechanical lumbar disc prosthesis.

Key Words Kineflex disc, degenerative disc disease, lumbar disc prosthesis, insertion technique, unconstrained disc prosthesis, Oswestry disability index. SAS Journal. Winter 2007; 1; 28-35. DOI: SASJ-2006-0005-RR

\section{INTRODUCTION}

Adjacent-level degeneration is a major concern in lumbar fusion operations. ${ }^{1-4}$ Lumbar artificial discs are an alternative to arthrodesis (fusion). The purpose of total disc replacement is to restore the intervertebral segment and protect the adjacent levels against abnormal loading conditions. A description of the surgical insertions of a lumbar prosthetic nucleus replacement, with a steel ball, was first published by Fernström. ${ }^{5}$ It failed clinically because of subsidence of the implant into the bony end plate. Modern total lumbar disc replacement commenced in 1984 with the insertion of the first-generation Charite disc prosthesis (Charité SB I, Raynham, Mass). The articular mechanism of this device was interposed between 2 bottle cap-shaped disc endplates. The mechanism 
of the prosthesis was carried through to the third-generation device still in use today (Charité SB III). The first results, from 16 patients, were published in $1987 .^{6,7}$ The failure at the boneendplate interface (subsidence) led to the second- and thirdgeneration articulated lumbar disc prostheses (Charité SB II and III). The second-generation disc had wings to increase the bearing surface and avoid subsidence into the bony endplate. Breakage through these wings and subsidence still occurred in this model. The third-generation disc has been used since 1987, and intermediate and long-term results are available. ${ }^{8-10}$ More recent publications report on prospective randomized cases in 2 US centers. ${ }^{11,12}$

More constrained lumbar disc prostheses have been developed. The US Food and Drug Administration (FDA) recently approved one of these prostheses, ProDisc (Synthes, West Chester, $\mathrm{Pa}$ ) and is evaluating Maverick (Medtronic Sofamor Danek, Memphis, Tenn); and FlexiCore (Stryker Spine, Allendale, New Jersey). Apart from the Charité disc prosthesis, the only other available disc with long-term follow-up is the lumbar ProDisc. ${ }^{13,14}$ Despite improvements in disc design and insertion techniques, difficulties persist with the correct midline and posterior placement of the prostheses within the disc spaces, even in experienced hands. ${ }^{12}$ No general consensus exists about indications and contraindications of total disc replacement. ${ }^{15}$

The Kineflex disc (SpinalMotion, Mountain View, Calif) is a chrome-cobalt-molybdenum (CCM) alloy (Biodur CCM Plus; Carpenter Technologies, Reading, Pa), unconstrained but recentering disc prosthesis with a mobile center of rotation. The mechanism consists of 2 metal endplates articulating over a sliding core positioned between the endplates (Figures 1 and 2). It allows 12 degrees of movement into flexion, extension, and left- and right-side bending. The inferior endplate has a retaining ring that limits the excursion in the inferior articulation to $2 \mathrm{~mm}$ in all directions and prevents dislodgment of the sliding core. The mechanism therefore only allows $4 \mathrm{~mm}$ of translation before distraction of the disc space, at which point a re-centering force is produced that counteracts the translation. The disc is inserted as a single unit with a freely mobile mechanism during the final insertion process to

Figure 1
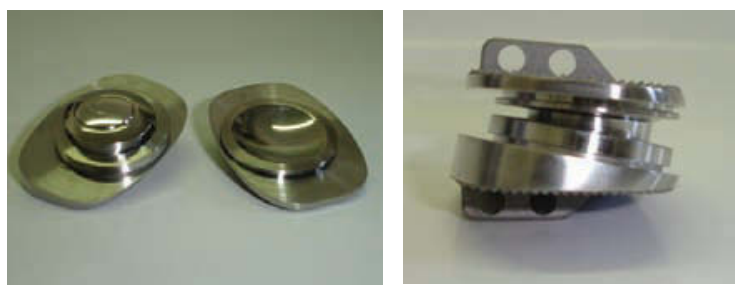

Kineflex metal-on-metal: mechanism,

(b) assembled
Figure 2
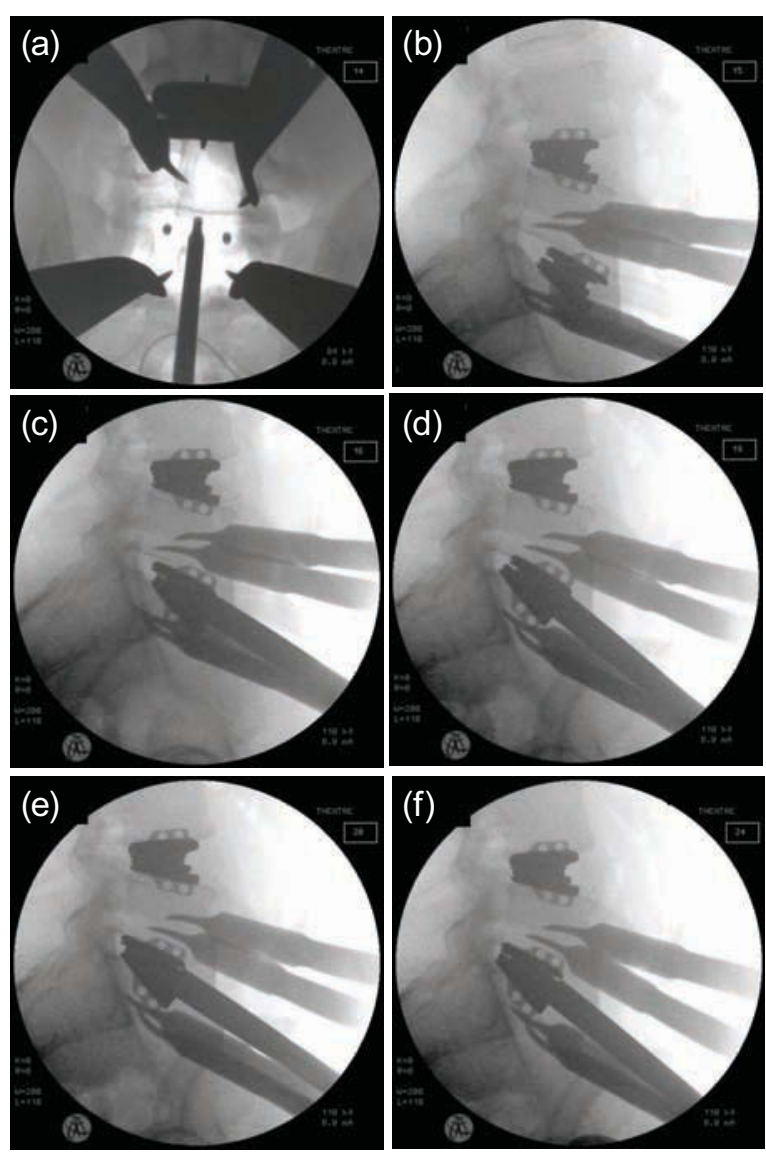

Insertion technique as seen on intraoperative radiographs: (a) midline finder in position, (b) initial engagement of the prosthesis into disc space, (c-f) sequential advancement of the prosthesis into final position.

facilitate placement posteriorly within the disc space. The disc was originally named "Centurion" because it was developed in Centurion (located between Pretoria and Johannesburg, South Africa). The objective in the development of this prosthesis and its insertion instrumentation was to facilitate, through a minimally invasive approach, reliable midline and posterior placement of the implant within the disc space even in severely degenerative disc spaces.

We present the properties of the implant, the insertion technique, and a 2-year clinical outcome of its first 100 patients and describe the relevant subgroups within this patient cohort.

\section{MATERIALS AND METHODS}

Our study consists of a single-center, consecutive, longitudinal series of the first 100 patients receiving 132 Kineflex lumbar disc replacements between October 2002 and May 2004. All discs were inserted by a single surgeon (U.R.H.). The primary 
diagnosis was degenerative disc disease with mechanical back or leg pain in all cases. All data were collected prospectively.

During clinical examinations, the patients had to physically indicate the painful areas of the back and lower limbs. Palpation of the interspinous spaces in both standing and prone positions determined the pain levels. Routine spinal examinations followed.

\section{Radiographic Evaluation}

All patients had a preoperative magnetic resonance imaging (MRI), lumbar myelography followed by computer tomography (Myelo-CT), or both MRI and Myelo-CT.

Preoperative and postoperative (at 3 months and at 1 year) and yearly, anteroposterior, lateral standing radiographs including the bottom endplate of the T12 vertebra and the top half of both femoral heads were performed. Lateral flexion-extension radiographs were also performed at these follow-ups; in addition, a lateral whole-spine standing radiograph was included. At all other follow-ups (2 weeks, 6 weeks, and 6 months), only standing anteroposterior side-bending and lateral flexionextension radiographs of the lumbar spine were performed. Oblique standing radiographs were only done preoperatively.

Preoperative discography was only performed in cases when, after clinical examination and radiographic evaluation, doubt persisted about inclusion or exclusion of a lumbar level in the operation. The amount of disc space narrowing, the presence or absence of spondylolysis, the mobility of the motion segment, and the radiological stability of the relevant spinal level were carefully assessed on the plain radiographs. Disc quality and amount of canal and recess encroachment by the disc, facet joints, and ligamentum flavum were determined by MRI. The degree of facet arthritis and modic changes were also assessed.

Preoperative disc height at the operated level was measured by 2 different observers on lateral standing radiographs at 3 points (anterior, middle, and posterior) and corrected by the magnification error. ${ }^{12}$

\section{Radiographic Placement Accuracy}

The exact central placement of all 132 disc implants in the coronal and midsagittal plane was determined and categorized, as described by McAfee et al., ${ }^{12}$ into ideal, suboptimal, and poor placement. The midsagittal plane on lateral radiograph is defined as $2 \mathrm{~mm}$ posterior to the middle of the vertebral body in the sagittal plane. The coronal plane on anteroposterior radiographs is the exact centerline of the vertebral body ${ }^{12}$ or interpedicular midpoint. ${ }^{16}$ The center of the core of the artificial disc was placed less than $3 \mathrm{~mm}$ of exact central placement in both the coronal and midsagittal planes in group I (ideal placement), $3 \mathrm{~mm}-5 \mathrm{~mm}$ from exact central placement in group II (suboptimal placement), and more than $5 \mathrm{~mm}$ from exact central placement in group III (poor placement). If the 2 axes were rated in different groups, the poorer rating determined the placement's rating. Two observers checked the measurements, which were then corrected by the magnification error. ${ }^{12}$

\section{Clinical Evaluation}

Inclusion criteria for the study were age of 18 years to 65 years, symptomatic single- or multilevel degenerative disc disease at the L2L3, L3-L4, L4-L5, or L5-S1 levels confirmed on X rays, MRI, and provocative discography in selected cases. Further inclusion criteria included mechanical back and leg pain, recurrent disc herniation, and broad-based central disc herniation without sequestration and junctional failure after previous fusion. All patients had failed conservative treatment of at least 6 months' duration. Only the symptomatic levels on clinical examination or discography were replaced.

Exclusion criteria were osteoporosis, tumor, infection, spondylolysis of the level, bony spinal stenosis, sequestrated disc prolapse tracking up or down behind the vertebral body, severe obesity, structural deformity, previous retroperitoneal surgery, vascular pathology, and previous wide laminectomy with destabilization of the facet complex. Advanced facet arthritis was not an exclusion criterion unless osteophyte formation from the facet resulted in bony canal or recess stenosis. Spinal or lateral recess stenosis caused by soft tissue (disc, ligamentum flavum, or joint capsule) was not a contraindication for disc replacement if proper decompression during surgery (direct or indirect) could be anticipated on preoperative imaging.

The primary clinical outcome measures for this study were pain relief and functional improvement as assessed by the 1-100 Oswestry Disability Index (ODI) ${ }^{17}$ and our own questionnaire. Patients completed both questionnaires preoperatively and at 6 weeks, 3 months, 6 months, 1 year, and 2 years in conjunction with the regular follow-up examinations. In addition to the outcome data, we collected general demographic information and operative data as well as data pertaining to radiological examination.

Our own questionnaire (designed by U.R.H. and I.R.W.) has not been validated. The questionnaire asked preoperative patients to gauge their pain in the past 2 weeks on a scale of 1 (no pain)

to 10 (pain as bad as it can be), to differentiate between back and leg pain and pain in different positions (lying, sitting, standing, walking). At follow-up visits we asked patients about their satisfaction with the outcome of the treatment operation (excellent, good, fair, poor). ${ }^{18} \mathrm{We}$ then asked patients if they would undergo the same operation again or recommend it to friends (yes, don't know, no). 


\section{Operative Technique}

All operations were performed on a translucent electrical table under radiographic image control. We used intraoperative cell saving on all patients. After a transverse midline incision of between $5 \mathrm{~cm}$ and $9 \mathrm{~cm}$, depending on patient size and number of levels to be exposed, the rectus sheet was opened, parallel to the linea alba, and the rectus muscle was retracted laterally. The surgeon approached the spine retroperitoneally, partially incising the transversus abdominis fascia from the arcade ligament cranially. After mobilizing the major vessels, the surgeon used Hohman retractors, attached to a frame retractor, to maintain exposure throughout the procedure. After a midline annuloplasty, the disc nucleus, the inner layer of the annulus, and any sequestrated disc material were removed. The endplates were prepared with a Cobbs instrument to remove the cartilaginous endplates and open curettes to prepare the bony endplates. Osteotomes and burrs were used rarely to remove big osteophytes or to prepare the endplates in cases of significant endplate sclerosis. This step was followed by sequential distraction of the disc space, with wedge distracters of increasing sizes. The midline was determined on anteroposterior radiographs with a specially designed and patented midline finder (Figure 2a). After the initial engagement of the assembled 3-part disc into the disc space (Figure 2b), with a fixed insertion device, the prosthetic disc mechanism was released. Further advancement into the disc space was accomplished with a released and fully mobile mechanism (Figure $2 \mathrm{c}-\mathrm{g}$ ). Our aim was to allow the leading edges of the disc to collapse, thus avoiding pressure and impact to the bony endplates of the vertebra. After closing the annuloplasty and final radiographic control, the surgeon closed the wound.

\section{Postoperative Mobilization}

Patients were allowed to ambulate the day after surgery without bracing. Patients restarted supervised gait training, isometric muscle strengthening, and stretching exercises from day 1 postoperatively. At discharge, patients were instructed to walk every day and were allowed to sit as long as they felt comfortable. Cycling on a stationary bike was encouraged after removal of stitches at 12 days after the operation. Light sports were allowed at 6 weeks, impact sports at 3-4 months.

All employed office workers were allowed to return to work at 4 weeks provided they could sit for prolonged periods without additional discomfort. Manual workers were kept off work for 6 weeks postsurgery and were allowed to go back on light duty (no lifting of more than $10 \mathrm{~kg}$, no vibration, limited bending, and no running) for the next 6 weeks.

\section{STATISTICAL METHODS}

Data are presented as mean \pm standard deviation. Group comparisons were made with a Mann-Whitney test or binomial test as appropriate. Wilcoxon matched-pairs test was used to compare baseline data with follow-up data. Data were analyzed on a personal computer with a commercially available statistical program (Statistica version 8; StatSoft, Tulsa, Okla). Significance was assumed at a 2-tailed value of $P<.05$.

\section{RESULTS}

Baseline characteristics of the study population are shown in Table 1. A 2-year full clinical outcome assessment was available for 98 of 100 patients. One patient was from a neighboring country and was only available for telephonic follow-up, and one patient was lost to follow-up.

Sixty-nine patients underwent single-level disc replacements and 31 patients had 2 levels replaced. Three of the single-level patients later received a second-level lumbar disc replacement at 7, 9, and 10 months after the index procedure, respectively. Twelve patients, who had a spondylolysis at a second level or had a transitional vertebra with abnormally developed facet joints, underwent fusions at that level during the index procedure. Four of these patients had undergone previous discectomies. Thirteen patients presented with adjacent level disc disease after previous instrumented posterolateral fusion surgery (1-7 previous operations). Another 28 patients in this series who underwent single or 2-level disc replacement had 1 to 4 previous discectomies or laminotomies (Table 1).

Operative times, estimated blood losses, and postoperative hospital stays are shown in Table 2.

\section{Recovery and Patient Satisfaction}

The average hospital stay was $2.8 \pm 0.8$ days (range, 2 to 8 days). Eighty-six patients were employed at the time of the operation. All went back to their previous occupation an average of 31.0 \pm 16.8 days after the operation. The pain score (1-10) of all patients dropped from $9.16 \pm 1.0$ preoperatively to $2.83 \pm 2.3$ at 1 year and $2.78 \pm 2.2$ at 2 years follow-up $(P<.01)$ (Figure 3 ).

The ODI improved significantly from $47.8 \pm 16$ preoperatively to $14.6 \pm 14.9$ at 1 year and $14.2 \pm 14.0$ at 2 years $(P<.01)$

(Figure 4). Eighty-seven percent of patients at 1 year and at $90 \%$ of patients at 2 years considered their clinical outcome to be good or excellent; $90 \%$ at 1 year and $92 \%$ at 2 years would undergo the same operation again or recommend it to friends. 
Table 1

Preoperative Characteristics of Study Population $(N=100)$

\begin{tabular}{|c|c|}
\hline & $\begin{array}{l}\text { No. or Mean } \pm \text { SD } \\
\quad \text { (Range) }\end{array}$ \\
\hline \multicolumn{2}{|l|}{ Gender } \\
\hline Men & 57 \\
\hline Women & 43 \\
\hline Age, y & $44.9(23-63)$ \\
\hline Height, cm & $174.6 \pm 9.6(154-196)$ \\
\hline Weight, kg & $81.3 \pm 15.6(47-138)$ \\
\hline Pain duration, months & $63.5 \pm 74.6(5-400)$ \\
\hline \multicolumn{2}{|l|}{ Non-operative care } \\
\hline Physical therapy & 99 \\
\hline Chiropractic care & 61 \\
\hline Acupuncture & 25 \\
\hline \multicolumn{2}{|l|}{ Previous surgery } \\
\hline Rizotomy & 15 \\
\hline Discectomy & 32 \\
\hline Laminectomy & 20 \\
\hline Fusion & 15 \\
\hline \multicolumn{2}{|l|}{ Smoking status } \\
\hline Smoking & 39 \\
\hline Nonsmoking & 61 \\
\hline \multicolumn{2}{|l|}{ Preoperative employment status } \\
\hline Employed & 86 \\
\hline Not employed & 11 \\
\hline Disabled & 2 \\
\hline Retired & 1 \\
\hline Claim or compensation patients & 8 \\
\hline
\end{tabular}

Two-level disc replacement patients scored better on pain score improvement and ODI improvement at 1 and 2 years compared with single level disc replacements $(P<.05)$ (Figures 3 and 4).

Patients who underwent isolated single or double level disc replacement who had undergone previous discectomies or laminectomies $(n=28)$ had similar outcome scores if compared with patients without previous spinal surgery (n $=46$ ). Their ODIs improved from $50.3 \pm 19.2$ to $16.5 \pm 17.2$ (no previous surgery: from $46.1 \pm 15.3$ to $11.0 \pm 15.3$ ) and
Table 2

Mean Operative Time, Blood Loss, and Length of Hospital Stay $(n=100)$

\begin{tabular}{|l|l|}
\hline Operative time, all patients, min & 130 (45-400) \\
\hline $\begin{array}{l}\text { Operative time, single level patients, min (48\% at L4/L5 } \\
\text { level) }\end{array}$ & $95.3 \pm 28.3$ \\
\hline Estimated blood loss, all patients, $\mathrm{ml}$ & $282 \pm 301$ \\
\hline $\begin{array}{l}\text { Estimated blood loss, single level patients, } \mathrm{ml} \text { (48\% at } \\
\text { L4/L5 level) }\end{array}$ & $145.7 \pm 153.2$ \\
\hline Hospital stay, all patients, days & $2.86 \pm 0.8$ \\
\hline
\end{tabular}

their pain score from $9.17 \pm 1.2$ to $3.1 \pm 1.9$ (no previous surgery: from $9.06 \pm 1.1$ to $2.41 \pm 2.2$ ) at 1 year.

\section{Radiographic Placement Accuracy}

Fifty-six percent of all operated disc levels had intervertebral disc heights of less than $5 \mathrm{~mm}$. Of the 100 patients, 93 patients with 124 implanted disc spaces underwent a preoperative MRI; the remaining 7 patients only had a preoperative MyeloCT. Eighty-three (67\%) instrumented disc spaces in $72(77 \%)$ patients showed adjacent modic changes on MRI scanning.

We determined and categorized the exact central placement of all 132 disc implants in the coronal and midsagittal planes. We assessed the radiographic accuracy of placement at 2 years. Most (125 [94.7\%]) discs were placed in ideal position, $6(4.5 \%)$ in suboptimal position, and $1(0.76 \%)$ had early subsidence (poor placement). Three of the suboptimal placements were in the coronal and 3 ( 1 of them extruded) in the sagittal plane. Except in the patient who had a traumatic extrusion of the lower endplate, there were no delayed migrations (change of position of more than $2 \mathrm{~mm}$ ). The 6 suboptimal placements were equally distributed between preoperative disc heights below $5 \mathrm{~mm}$ and above $5 \mathrm{~mm}$, meaning there was no correlation between preoperative intervertebral disc height narrowing and decreased radiological placement accuracy.

\section{Complications and Reoperations}

There were no procedure-related deaths. Approach-related complications included 2 cases of deep vein thrombosis, 4 venous vascular injuries (blood loss $<500 \mathrm{ml}$ ), 2 cases with transient neuropraxia of a L5 nerve root, and 6 patients with a postoperative warmer left leg (1 permanent).

Six patients $(6 \%)$ required a reoperation. Three patients $(3 \%)$ had disc level-related complications requiring reoperations as follows: One patient had an incomplete decompression and was re-decompressed 2 days after the index surgery. The same 
disc was reinserted. Another patient had a traumatic partial endplate protrusion at 5 weeks. The disc was removed and converted into an anterior fusion. In a third patient, with major subsidence, the disc was removed at 2 weeks, the vertebra was bone grafted, and a larger endplate disc was inserted (see mention of poor placement accuracy in the previous paragraph).

Three patients (3\%) underwent a second-level disc replacement procedure. All reoperated patients received further follow-up, and their assessments were included in the outcome results.

\section{DISCUSSION}

The Kineflex disc prosthesis has 3 features distinguishing it from other disc prostheses: (1) The mechanism of the prosthesis is unconstrained but re-centering, with a retaining ring on the inferior endplate to maintain the sliding core in position. (2) Two material options for the articulating surfaces are currently available (CCM on polyethylene and CCM on CCM). (3) The final seating into the disc space is accomplished with a fully released articulating mechanism to take pressure off the implant-bone interface at the leading edges of the implant during the insertion. The aim is to minimize the danger of bony endplate violation.

There are certain differences between the mechanisms in motion behavior of the Kineflex prosthesis and 2 other mobile core discs: the Charite prosthesis, already approved by the US FDA, and the Mobidisc (LDR Medical, Troyes, France), under investigation by the US FDA. Compared with the Charite disc, the mechanism of the Kineflex prosthesis has a stronger re-centering vector because of the more restricted inferior excursion. With creep occurring in the connection between the retaining ring and the inner core of the Charite disc, the re-centering force would further decrease. The Mobidisc has no intrinsic re-centering force within the limits of the excursion of the inferior articulation. No tilting of the sliding core occurs. When the Mobidisc reaches the limit of the inferior articulation, which happens unconstrained, there will be a sudden change in motion pattern. With further excursion the Mobidisc mechanism behaves like a semiconstrained prosthesis (e.g., ProDisc, Maverick). The US FDA is currently evaluating the metal-on-metal Kineflex disc.

More than $50 \%$ of patients in our series had advanced disc degeneration with disc space height of less than $5 \mathrm{~mm}$, some with advanced facet joint arthritis. In significantly collapsed and rigid disc spaces, we specifically aim to achieve a posterior position of the prosthesis within the disc space to remove the load from the facets. This achievement has been difficult with other implants because of the rigidly held implants during the insertion process. The Kineflex disc prosthesis is disconnected from its insertion tool after the initial engagement into the disc space. The final placement is done with a released prosthetic mechanism allowing the leading edges to adapt to the contour of the bony disc space. This mechanism facilitates the seating of the prosthesis, avoiding excessive pressure on the bony endplate during insertion. Exact posterior position of the prosthesis within the disc space has been achieved and maintained in $98 \%$ of patients and therefore compares favorably with other implants. ${ }^{12}$ The radiographic placement accuracy achieved was equally good in patients with preoperative intervertebral disc heights below and above $5 \mathrm{~mm}$.

Operative time and blood loss were higher than in other studies. ${ }^{10,11}$ Twelve of our patients had additional fusion surgery, including combined posterior and anterior osteotomy surgery, with operative times of up to 7 hours. These cases added to operative time and blood loss. The use of Hohman retractors for exposure causes additional bleeding from the vertebral bodies. However, for single-level disc replacements, the operative time and blood loss are comparable to other studies (Table 2). ${ }^{10,11}$

Postoperative hospital stay and return to work data compare favorably with other studies. ${ }^{8-11}$ All patients who were previously employed went back to work an average of 31 days after the operation. The ODI and pain score improvements occurred early after surgery and were maintained at 1- and 2-year follow-up (Figures 3 and 4). Two-level replacement patients scored better on clinical outcome parameters than the single-level replacement patients. Similar results were shown by Bertagnoli et al. ${ }^{19,20}$ but contradicted by others. ${ }^{21}$ We only replaced the clinically or discographically confirmed disc level in 2-level and multilevel degeneration. Three of our single-level replacements required a second-level disc replaced during the 2-year follow-up period. Although we included multilevel disease in our series we did not perform surgery on all affected levels. We only included levels at L3-4 and cranial to it in cases when clinical examination, radiculopathy, or a significantly positive discogram demonstrated their role as pain generators.

The improvement in the ODI scores is comparable with that found elsewhere. ${ }^{11,12,19,20}$ Of particular interest are the preliminary results in 13 patients who had junctional disc replacement after previous posterolateral instrumented fusion operations. These 13 patients had undergone 36 previous spinal procedures before the index procedure. All of these patients presented with significant flat-back deformities from inadequate restoration of lordosis during the previous

posterolateral instrumented fusion. One needs to consider that revision surgery in these patients has a high failure rate as far as patient satisfaction is concerned. ${ }^{22-25}$ Salvage surgery usually includes combined anterior and posterior spinal surgery ${ }^{23-25}$ or posterior extension osteotomies with extension of the fusion. ${ }^{23}$ 
In our opinion, an isolated single-level disc replacement after previous fusion surgery can only correct a limited degree of lumbar flat-back deformity. We therefore perform, at the time of the index procedure, an additional spinal osteotomy through the fusion site in cases with severe flat-back deformity. Eleven of 13 patients considered their 2-year outcome to be good or excellent, and 12 would undergo the same procedure again. Despite three reoperations in this subgroup, we consider junctional decompensation after fusion a good indication for total disc prosthesis provided that good spinal alignment can be achieved during surgery. Bertagnoli et al. presented larger numbers and longer follow-up times in this particular patient group, ${ }^{26}$ with excellent clinical outcome. Other previous publications on disc replacement after fusion surgery had very short follow-up times or numbers of patients..$^{27,28}$

Good short-term clinical results were achieved with the Kineflex disc in a heterogeneous patient group including a high number of patients with advanced disc degeneration, severe disc space narrowing, and previous fusion with lumbar flat-back deformity. Accurate placement of the prosthesis can be achieved in the sagittal and coronal planes.

Ulrich R. Hähnle, MD, FCS (Ortho), Ian R. Weinberg, MD, FCS (Neuro), Karen Sliwa, MD, PhD, Barry MBE Sweet, MD, $\mathrm{PhD}$, and Malan de Villiers, $\mathrm{PhD}$

From the Department of Orthopedic Surgery, University of the Witwatersrand, Johannesburg, South Africa (Hähnle and Sweet); Linksfield Park Clinic, Johannesburg (Hähnle and Weinberg); Department of Medicine, University of the Witwatersrand (Sliwa); Department of Mechanical Engineering, University of Potchefstrom, Potchefstrom; South Africa (de Villiers); and Southern Medical, Wapadrand, South Africa (de Villiers).

Ulrich R Hähnle, Ian R Weinberg, and Malan de Villiers are codevelopers of the Kineflex disc and shareholders in SpinalMotion, Mountain View, Calif.

Address correspondence and reprint requests to Ulrich Hähnle, PO Box 52040, Saxonwold 2132, Johannesburg, South Africa (email: hahnleu@mdh-africa.org).

This submission was received January 8, 2006, and accepted for publication February 26, 2007.

We thank Stephanie Hanekom and Aldori Gehring for their enthusiastic help with patient management and follow-up.

The institutional review board of the hospital where all the cases have been performed (Linksfield Park Clinic, Nedcare, Johannesburg, South Africa) approved this study, which was conducted in accordance with the ethical standards of the Declaration of Helsinki (2000).

\section{REFERENCES}

1. Gillet P. The fate of the adjacent motion segments after lumbar fusion. J Spinal Disord Tech. 2003;16(4):338-345.

2. Kumar MN, Jacquot F, Hall H. Long-term follow-up of functional outcomes and radiographic changes of adjacent levels following lumbar spine fusion for degenerative disc disease. Eur Spine J. 2001;10:309-313.

3. Lehmann TR, Spratt KF, Tozzi JE, et al. Long-term followup of lumbar fusion patients. Spine. 1987;12:97-104.

4. Park P, Garton HJ, Gala VC, Hoff JT, McGillicuddy JE. Adjacent segment disease after lumbar or lumbosacral fusion: review of the literature. Spine. 2004;29(17):19381944.

5. Fernström U. Arthroplasty with intercorporal endoprosthesis in herniated disc and in painful disc. Acta Chir Scand. 1966;355:154-159.

6. Büttner-Janz K, Schellnack K, Zippel H. Eine alternative BehandlungsstrategiebeimlumbalenBandscheibenschaden mit der Bandscheiben-endoprothese Modulartyp SB Charité. Z Othop. 1987;125:1-6.

7. Büttner-Janz K, Schellnack K. Bandscheibenendoprothetik. Entwicklungsweg und gegenwärtiger Stand. Beitr Othop Traumatol. 1990;37:137-147.

8. David T. Lumbar disc prosthesis: A study of 85 patients reviewed after a minimum follow-up period of five years. Rachis. 1999;11:4-5.

9. Griffith SL, Shelokov AP, Büttner-Janz K, LeMaire JP, Zeegers WS. A multicenter retrospective study of the clinical results of the LINK SB Charité intervertebral prosthesis. Spine. 1994;19:1842-1849.

10. Lemaire JP, Carrier H, Sariali el-H, Skalli W, Lavaste F. Clinical and radiological outcomes with the Charité artificial disc: A 10-year minimum follow-up. J Spinal Disord Tech. 2005;16(4): 353-359.

11. Blumenthal S, McAfee PC, Guyer R, et al. A prospective, randomized, multicenter Food and Drug Administration investigational device exemption study of lumbar total disc replacement with the Charite artificial disc versus lumbar fusion, part I: Evaluation of clinical outcome 
[published correction appears in Spine. 2005;30:2356]. Spine. 2005;30:1565-1575.

12. McAfee PC, Cunningham B, Holsapple G, et al. A prospective, randomized, multicenter Food and Drug Administration investigational device exemption study of lumbar total disc replacement with the Charité artificial disc versus lumbar fusion, part II: Evaluation of radiographic outcomes and correlation of surgical technique accuracy with clinical outcomes. Spine. 2005;30:1576-1583.

13. Marnay T. Lumbar disc replacement: 7-10 year results with the ProDisc. Eur Spine J. 2002;11:S19.

14. Tropiano P, Huang RC, Girardi FP, Cammisa FP Jr, Marnay T. Lumbar total disc replacement: Seven to eleven-year followup. J Bone Joint Surg Am. 2005;87:490-496.

15. Huang RC, Lim MR, Girardi FP, Cammisa FP Jr. The prevalence of contraindications to total disc replacement in a cohort of lumbar surgical patients. Spine. 2004;29(22):2538-2541.

16. Mistry DN, Robertson PA. Radiological landmark accuracy for optimum coronal placement of total disc arthroplasty. $J$ Spinal Disord Tech. 2006;19(4):231-236.

17. Fairbank JC, Pynsent PB. The Oswestry Disability Index. Spine. 2000;25:2940-2952.

18. Tafazal S I, Sell PJ. Outcome scores in spinal surgery quantified: excellent, good, fair and poor in terms of patient-completed tools. Eur Spine J. 2006;15:1653-1660.

19. Bertagnoli R, Yue JJ, Shah RV, et al. The treatment of disabling multilevel lumbar discogenic low back pain with total disc arthroplasty utilizing the ProDisc prosthesis: a prospective study with 2-year minimum follow-up. Spine. 2005;30(19):2192-2199.

20. Bertagnoli R, Yue JJ, Shah RV, et al. The treatment of disabling single-level lumbar discogenic low back pain with total disc arthroplasty utilizing the ProDisc prosthesis: a prospective study with 2-year minimum follow-up. Spine. 2005;30(19):2230-2236.

21. Siepe CJ, Mayer HM, Wiechert K, Korge A. Clinical results of lumbar disc replacement with ProDisc II: three-year results for different indications. Spine. 2006:31(17):1923-1932.

22. Fritsch EW, Heisel J, Rupp S. The failed back surgery syndrome. Spine. 1996;21(5):626-633.

23. Lagrone MO, Bradford DS, Moe JH, Lonstein JE, Winter RB, Ogilvie JW. Treatment of symptomatic flatback after spinal fusion. J Bone Joint Surg Am. 1988;70(4):569-580.
24. Slosar PJ, Reynolds JB, Schofferman J, Goldthwaite N, White AH, Keaney D. Patient satisfaction after circumferential lumbar fusion. Spine. 2000;25:722-726.

25. Stewart G, Sachs BL. Patient outcome after reoperation on the lumbar spine. J Bone Joint Surg Am. 1996;78:706711.

26. Bertagnoli R, Yue JJ, Fenk-Mayer A, Eerulkar J, Emerson JW. Treatment of symptomatic adjacentsegment degeneration after lumbar fusion with total disc arthroplasty by using the ProDisc prosthesis: a prospective study with 2-year minimum follow up. J Neurosurg Spine. 2006;4(2):91-97.

27. Enker P, Steffee A, McMillin C, Keppler L, Biscup R, Miller S. Artificial disc replacement. Preliminary report with a 3-year minimal follow-up. Spine. 1993;18(8):10611070.

28. Kim WJ, Lee SH, Kim SS, Lee C. Treatment of juxtafusional degeneration with artificial disc replacement (ADR): Preliminary results of an ongoing prospective study. J Spinal Disord Tech. 2003;16(4):390-397. 